\title{
Investigating the association between polymorphisms in connective tissue growth factor and susceptibility to colon carcinoma
}

\author{
ABRAR AHMAD ${ }^{1}$, SHLEAR ASKARI $^{1}$, RAHEL BEFEKADU ${ }^{2}$ and VICTORIA HAHN-STRÖMBERG ${ }^{1}$ \\ ${ }^{1}$ Department of Clinical Medicine, Örebro University, Örebro 701 81; ${ }^{2}$ Department of Laboratory Medicine, \\ Section for Transfusion Medicine, Örebro University Hospital, Örebro 701 85, Sweden
}

Received March 4, 2014; Accepted July 25, 2014

DOI: $10.3892 / \mathrm{mmr} .2014 .3083$

\begin{abstract}
There have been numerous studies on the gene expression of connective tissue growth factor (CTGF) in colorectal cancer, however very few have investigated polymorphisms in this gene. The present study aimed to determine whether single nucleotide polymorphisms (SNPs) in the CTGF gene are associated with a higher susceptibility to colon cancer and/or an invasive tumor growth pattern. The CTGF gene was genotyped for seven SNPs (rs6918698, rs1931002, rs9493150, rs12526196, rs12527705, rs9399005 and rs12527379) by pyrosequencing. Formalin-fixed paraffin-embedded tissue samples $(n=112)$ from patients diagnosed with colon carcinoma, and an equal number of blood samples from healthy controls, were selected for genomic DNA extraction. The complexity index was measured using images of tumor samples $(n=64)$ stained for cytokeratin-8. The images were analyzed and correlated with the identified CTGF SNPs and clinicopathological parameters of the patients, including age, gender, tumor penetration, lymph node metastasis, systemic metastasis, differentiation and localization of tumor. It was demonstrated that the frequency of the SNP rs6918698 GG genotype was significantly associated $(\mathrm{P}=0.05)$ with an increased risk of colon cancer, as compared with the GC and CC genotypes. The other six SNPs (rs1931002, rs9493150, rs12526196, rs12527705, rs9399005 and rs12527379) exhibited no significant difference in the genotype and allele frequencies between patients diagnosed with colon carcinoma and the normal healthy population. A trend was observed between genotype variation at rs6918698 and the complexity index $(\mathrm{P}=0.052)$. The complexity index and genotypes for any of the studied SNPs were not significantly correlated with clinical or pathological parameters of the patients. These results indicate that the rs6918698 GG
\end{abstract}

Correspondence to: Mr. Abrar Ahmad, Department of Clinical Medicine, Örebro University, Södra Grev Rosengatan 32, Örebro 702 81, Sweden

E-mail: ibrarsandila@yahoo.com

Key words: genotyping, clinicopathological parameters, pyrosequencing genotype is associated with an increased risk of developing colon carcinoma, and genetic variations at the rs6918698 are associated with the growth pattern of the tumor. The present results may facilitate the identification of potential biomarkers of the disease in addition to drug targets.

\section{Introduction}

Connective tissue growth factor (CTGF), also termed CCN-2 (cysteine rich 61/connective tissue growth factor/nephroblastoma), is a prototypical member of the CCN family. CTGF, similar to other CCN family members, is recognized for its diverse role in cellular processes, including cell proliferation, development, adhesion, angiogenesis, migration and tumorigenesis (1-4). Previous studies have indicated that CTGF is activated by basic fibroblast growth factor (bFGF) and vascular endothelial growth factor (VEGF) $(3,4)$. One of the principal regulators of CTGF production is transforming growth factor $\beta$ (TGF- $\beta$ ), which functions in tumor initiation and progression $(5,6)$.

In vitro studies have indicated that, when the functional effect of CTGF is blocked by antagonists, the proliferation and migration of endothelial cells is reduced (7). Overproduction of CTGF is implicated in fibroproliferative diseases such as pulmonary fibrosis, systemic sclerosis and liver cirrhosis (8-12). Due to diverse autocrine and paracrine actions, CTGF can have negative effects on normal physiological functions, which implicates CTGF as a potential target for therapeutic purposes (8).

The gene expression of CTGF and its association with cancer development has been studied in various cancers, including colorectal cancer (CRC), and CTGF is considered a prognostic marker in multiple types of human carcinoma (13-17). However, a consensus has not been reached on the role of CTGF in tumorigenesis. In studies by Jacobson and Cunningham (4), Zhen et al (18) and Ladwa et al (19), CTGF was demonstrated to produce opposing effects in different tumor types, and even within the same type of tumor, which can be categorized into three forms: 'Oncogenic', 'tumor suppression' and 'complex' with both properties. Due to the aberrant expression levels in different types of tumor, the overall role of the $\mathrm{CCN}$ protein family members in cancer remains unclear (11,20-22).

Studies investigating polymorphisms in growth factor and other genes demonstrate that they have the ability to induce 
prominent changes in normal functions via the alteration of transcription sites $(23,24)$. Various genotypes that are changed as a result of polymorphisms are involved in different pathological conditions, and can provide information regarding the susceptibility, severity and prognosis of disease (21). For example, CTGF polymorphisms have been overrepresented in patients with systemic sclerosis, hepatic fibrosis and diabetes mellitus nephropathy; however, there have been few conclusive studies on the function of CTGF SNPs in disease susceptibility $(9,11,12)$. Genetic variations in CTGF are rarely used in clinical decision-making, as there are very few studies concerning CTGF polymorphisms in cancer.

Tumor growth and size are important variables for the prognosis of CRC. Various techniques have been introduced for the analysis of tumor growth in different types of carcinoma, but a single widely-accepted set of criteria for grading is required (25). The majority of grading systems stratify a tumor semi-quantitatively into 3-4 grades, in which 1 indicates a high level of differentiation and 4 indicates poor differentiation (26). The infiltrative pattern of a tumor can be distinguished by its invasive front, which can aid prognosis (27). The invasive front is a term used to describe the level of tumor growth into adjacent tissues. The invasive front can be categorized as expansive and infiltrative, in which the infiltrative growth pattern has an irregular invasive front and poorer prognosis, while the expansive growth pattern has a smooth invasive front $(28,29)$. In 2008, a computer software-based technique for measuring the invasiveness of tumors in CRC was introduced by Franzén et al (30) in which they quantitatively scored tumors on a scale of 1-5, and labelled the measurement as the complexity index (CI). A grade 1 tumor was defined as having a smooth invasive front, while a grade 5 tumor was defined as having a highly irregular tumor front in addition to separate tumor cells and cell clusters. This classification was based on the fractile dimensions and the number of tumor cells (30).

Tumor growth depends upon numerous proteins that are important in maintaining the morphology of tissues and affect invasion and metastasis $(10,31)$. Tumors present limitations with respect to therapy, due to their infiltrative nature, which inhibits complete resection and contributes to tumor recurrence and resistance to radio- and chemotherapy (32). Previous studies have demonstrated that the complexity index of a tumor is associated with tumor wall penetration, progression and stage $(33,34)$. As the action of CTGF in the metastasis, proliferation and migration of tumor cells is well-established $(2,35,36)$, it was assumed in the current study that genetic variation is able to cause changes in the tumor phenotype, which can affect the CI of the tumor.

Polymorphic alleles of various growth factors such as VEGF, TGF- $\beta$ and bFGF have been well-defined with respect to their potential role in CRC development (37-39). Currently, a limited number of studies investigating the role of CTGF in CRC have been published, and genetic variations in this gene have yet to be studied in patients with CRC. The aim of the current study was to assess the following SNPs in the CTGF gene in patients diagnosed with CRC: rs6918698, rs1931002, rs9493150, rs12526196, rs12527705, rs9399005 and rs12527379. This was then compared with the normal healthy population, in addition to comparing the SNPs in patients with different clinicopathological parameters, including age, gender, tumor wall penetration, lymph node metastasis, systemic metastasis, localization and tumor differentiation. Five-year survival data from the patients associated with genetic variations was produced, in order to gain information regarding the role of CTGF and genotypes associated with the risk of development of CRC.

\section{Materials and methods}

Patient material. A total of 112 formalin-fixed paraffin-embedded (FFPE) samples from patients diagnosed with CRC at the Department of Laboratory Medicine, section for Pathology, Örebro University Hospital (Örebro, Sweden) between 2004 and 2009 were selected. Rectal carcinoma samples were not used, as rectal carcinoma is often treated with radiation prior to surgery, which can alter the morphological and genetic characteristics of the tumor. Blood samples from 112 blood and plasma donors were used as controls. An initial screening of patient and control samples ( $n=67$ of each) was performed for seven known SNPs in CTGF (rs6918698, rs1931002, rs9493150, rs12526196, rs9399005, rs12527379 and rs12527705). Following evaluation of the results, samples that showed significance or a trend toward significant association between polymorphism and disease were processed, resulting in 112 CRC samples and 112 normal blood samples. These samples $(n=112)$ were analyzed for the following SNPs: rs6918698, rs1931002, rs9493150, rs12526196 and rs12527705. Two SNPs (rs9399005 and rs12527379) were analyzed in 67 patient and 67 control samples. The samples were collected from both males and females. The present study was approved by the Ethical Review Board, EPN (Uppsala, Sweden).

DNA extraction. The tumor area was outlined by an experienced morphologist (Hahn-Strömberg). Depending upon the size of the tumor samples, 1-2 tissue punches of 2-mm diameter were obtained from the tumor area in the FFPE blocks. Genomic DNA was extracted from this area using a NucleoSpin ${ }^{\circledR}$ FFPE DNA kit (Macherey-Nagel GmbH, Düren, Germany) according to the manufacturer's instructions. Genomic DNA from blood and plasma donors was extracted using a NucleoSpin ${ }^{\circledR}$ Blood DNA Extraction kit (Macherey-Nagel $\mathrm{GmbH}$ ) and the concentration and quality of the DNA was analyzed using a NanoDrop 1000 spectrophotometer (Thermo Fisher Scientific, Wilmington, DE, USA).

Primer designin and optimization. Primers were designed using PyroMark Assay DesignSoftware, version 2.0 (Qiagen, Hilden, Germany). The primers were optimized by polymerase chain reaction (PCR) at different temperatures and $\mathrm{MgCl}_{2}$ concentrations. The primer sequences (forward, reverse and sequencing primers) and their annealing temperatures are presented in Table I.

$P C R$. A master mix was prepared, containing the following reagents: Reverse and forward primers $(0.25 \mu \mathrm{M})$ (Biomers.net $\mathrm{GmbH}, \mathrm{Ulm}$, Germany) KAPA2G Buffer M(1X), KAPA $\mathrm{MgCl}_{2}$ (1 mM), KAPA dNTP Mix (200 $\mu \mathrm{M})$, KAPA2G Fast HotStart DNA Polymerase (1 U) (KAPA2G Fast HotStart PCR kit, KK5512; Kapa Biosystems, Inc., Wilmington, MA, USA) and genomic DNA (90-100 $\mu \mathrm{g})$. PCR reactions were conducted in 
Table I. Forward, reverse and sequencing primers used to analyze seven single nucleotide polymorphisms in connective tissue growth factor.

\begin{tabular}{|c|c|c|c|}
\hline SNP number & Primers & Annealing temperature $\left({ }^{\circ} \mathrm{C}\right)$ & Amplicon length (bp) \\
\hline rs6918698 & $\begin{array}{l}\text { F: GGGGCAGATTTCCAAAACTCTT } \\
\text { R: TGGATCCCTTTTTCTGGAAACA } \\
\text { S: AACATTGATGGCCACT }\end{array}$ & 54 & 112 \\
\hline rs1931002 & $\begin{array}{l}\text { F: CCCATAGGCATGGTTATTTAAAGA } \\
\text { R: AGCAAACTTGGTAGCCAGTATGT } \\
\text { S: TTTAGAAACTCTTTGGATGA }\end{array}$ & 54 & 116 \\
\hline rs9493150 & $\begin{array}{l}\text { F: TCAGAGCATGGGTTCAAGATAA }{ }^{\mathrm{a}} \\
\text { R: CAGGCTGTTTTCAAATGATAAATC } \\
\text { S: CCGATCTTTGCACCA }\end{array}$ & 53 & 111 \\
\hline rs12526196 & $\begin{array}{l}\text { F: AGAGGAAAATCGTTCACCATTTTA } \\
\text { R: TACATGCAACACACATCGAATCTC } \\
\text { S: AAGACAACACTGAATATACA }\end{array}$ & 52 & 113 \\
\hline rs12527705 & $\begin{array}{l}\text { F: CAATGGTGCTCCTCATTTCTT } \\
\text { R: GGATTCAAAGCAATAGACATGTAG } \\
\text { S: GCAATAGACATGTAGACCC }\end{array}$ & 52 & 94 \\
\hline rs9399005 & $\begin{array}{l}\text { F: TGATGTGAAGGGTTGGAAACTAA }{ }^{\mathrm{a}} \\
\text { R: TCAGTCTCCATTAACCCTGTTGTA } \\
\text { S: GCATTTGTACCTCTCTGG }\end{array}$ & 54 & 93 \\
\hline rs12527379 & $\begin{array}{l}\text { F: AGCTTTCTCССТСТСТССTTTAA } \\
\text { R: CCTCTCTCTCTGCCATGTGTAGTTª } \\
\text { S: ATGTTGTTAATGGAATGC }\end{array}$ & 54 & 111 \\
\hline
\end{tabular}

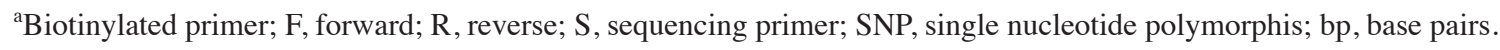

an ABI 2720 Thermal Cycler (Life Technologies, Carlsbad, CA, USA) in three steps as follows: (i) Denaturation at $95^{\circ} \mathrm{C}$ for $10 \mathrm{~min}$; (ii) 49 cycles with denaturation at $94^{\circ} \mathrm{C}$ for $45 \mathrm{sec}$, annealing temperature (according to optimized annealing temperature of primers) for $30 \mathrm{sec}$, and extension at $72^{\circ} \mathrm{C}$ for $30 \mathrm{sec}$; (iii) an extension was completed at $72^{\circ} \mathrm{C}$ for $7 \mathrm{~min}$.

Gel electrophoresis. High-resolution agarose (Sigma-Aldrich, St. Louis, MO, USA) was added to $1 \mathrm{X}$ TBE (Tris base, acetic acid and EDTA) buffer solution to produce a $2 \%$ solution of agarose. A MassRuler Low Range DNA Ladder (Thermo Fisher Scientific, Pittsburgh, PA, USA) was used to compare the amplicon sizes following agarose gel separation. The PCR products were visualized using a UV Transilluminator (Bio-Rad Laboratories AB, Sundbyberg, Sweden).

Polymorphism screening by pyrosequencing. Pyrosequencing was performed using a PyroMark Q96 ID sequencing and quantification platform (Qiagen AB, Sollentuna, Sweden). A master mix solution of Streptavidin Sepharose High Performance Beads (GE Healthcare, Uppsala, Sweden) was prepared by diluting sepharose beads in ultra-pure Milli-Q water and $1 \mathrm{X}$ binding buffer ( $1 \mathrm{mM} / 1$ EDTA, $0.1 \%$ Tween $20,2 \mathrm{M} / 1$ $\mathrm{NaCl}, 10 \mathrm{mM} / 1$ Tris-HCl, Milli-Q water; $\mathrm{pH}$ 7.6). The streptavidin solution was added to a 96-well PCR plate, followed by the addition of the amplified PCR product from each sample. Another solution was prepared for the sequencing primer by diluting it to $0.5 \mu \mathrm{M}$ with $1 \mathrm{X}$ annealing buffer $(2 \mathrm{mM} / 1$ magnesium acetate, $20 \mathrm{mM} / 1$ Tris-acetate; $\mathrm{pH}$ 7.6) at a ratio of 1:249 and adding it to a PSQ96 well plate. A PyroMark Q96 Vacuum Workstation (Qiagen, Hilden, Germany) was used to purify the biotinylated PCR product. Following purification, the PSQ96 plate was heated at $80^{\circ} \mathrm{C}$ for $2 \mathrm{~min}$ and was left to cool at room temperature for $10 \mathrm{~min}$. The polymorphisms were analyzed using PyroMark ID software, version 1.0 (Qiagen AB, Upsala, Sweden). The substrate mixture, enzymes and dNTPs were added to the cartridge according to calculation generated by the PyroMark Q 96 ID system (Qiagen AB, Uppsala, Sweden). A PyroMark Gold Q96 Reagent kit (Qiagen AB, Uppsala, Sweden) was used according to manufacturer's instructions.

CI. To calculate the CI, 64 tumor samples were randomly selected for computer image analysis from one patient group used for the CTGF SNP study. Slide preparations, including sectioning, staining and image processing were performed using the methodology as described by Franzén et al (30). In brief, images from the invasive front of the tumor area were captured using a Leica DC200 digital camera mounted on a Leica DMRXE microscope with 10X objective lens (Leica Microsystems GmbH, Wetzlar, Germany). From 
Table II. Genotypes in connective tissue growth factor and their association as risk factors for colorectal cancer.

\begin{tabular}{|c|c|c|c|c|c|c|c|}
\hline CTGF SNPs & Genotype & $\begin{array}{l}\text { Total CRC and } \\
\text { control samples } \\
\text { (\% all samples) }\end{array}$ & $\begin{array}{c}\text { Control } \\
\text { (\% controls) }\end{array}$ & $\begin{array}{c}\text { CRC } \\
(\% \text { CRC) }\end{array}$ & P-value & OR & $95 \% \mathrm{CI}$ \\
\hline \multirow[t]{3}{*}{ rs6918698 } & $\mathrm{CC}$ & $64(28.6)$ & $35(31.2)$ & $29(25.9)$ & 0 & 1.00 & (Referent) \\
\hline & GC & $115(51.3)$ & $61(54.5)$ & $54(48.2)$ & 0.833 & 1.068 & $0.579-1.973$ \\
\hline & GG & $45(20.1)$ & $16(14.3)$ & $29(25.9)$ & 0.050 & 2.187 & $0.999-4.79$ \\
\hline \multirow[t]{3}{*}{ rs1931002 } & GG & $198(88.4)$ & $98(87.5)$ & $100(89.3)$ & 0 & 1.00 & (Referent) \\
\hline & GA & $23(10.3)$ & 13 (11.6) & $10(8.9)$ & 0.524 & 0.75 & $0.316-1.8$ \\
\hline & AA & $3(1.3)$ & $1(0.9)$ & $2(1.8)$ & 0.585 & 1.96 & $0.175-21.966$ \\
\hline \multirow[t]{3}{*}{ rs9493150 } & $\mathrm{CC}$ & $129(57.6)$ & $67(59.8)$ & $62(55.4)$ & 0 & 1.00 & (Referent) \\
\hline & GC & $81(36.2)$ & $40(35.7)$ & $41(36.6)$ & 0.718 & 1.108 & $0.635-1.93$ \\
\hline & GG & $14(6.2)$ & $5(4.5)$ & $9(8)$ & 0.255 & 1.945 & $0.618-6.122$ \\
\hline \multirow[t]{3}{*}{ rs12526196 } & $\mathrm{TT}$ & $183(81.7)$ & 94 (83.9) & $89(79.5)$ & 0 & 1.00 & (Referent) \\
\hline & $\mathrm{TC}$ & $34(15.2)$ & $18(16.1)$ & $16(14.3)$ & 0.866 & 0.939 & $0.451-1.954$ \\
\hline & $\mathrm{CC}$ & $7(3.1)$ & $0(0)$ & $7(6.2)$ & 0.999 & N/A & N/A \\
\hline \multirow[t]{3}{*}{ rs12527705 } & $\mathrm{TT}$ & $162(72.3)$ & 78 (69.6) & $84(75.0)$ & 0 & 1.00 & (Referent) \\
\hline & AT & $57(25.4)$ & $34(30.3)$ & $23(20.5)$ & 0.137 & 0.628 & $0.341-1.159$ \\
\hline & AA & $5(2.2)$ & $0(0)$ & $5(4.4)$ & 0.9999 & N/A & N/A \\
\hline \multirow[t]{3}{*}{ rs9399005 } & GG & $63(47)$ & $34(50.7)$ & $29(43.3)$ & 0 & 1.00 & (Referent) \\
\hline & GA & $61(45.5)$ & $29(43.3)$ & $32(47.8)$ & 0.474 & 1.294 & $0.639-2.62$ \\
\hline & AA & $10(7.5)$ & $4(6)$ & $6(9)$ & 0.415 & 1.759 & $0.452-6.843$ \\
\hline \multirow[t]{3}{*}{ rs12527379 } & GG & $41(30.6)$ & $17(25.4)$ & $24(35.8)$ & 0 & 1.00 & (Referent) \\
\hline & GA & $65(48.5)$ & $37(55.2)$ & $28(41.8)$ & 0.123 & 0.536 & $0.243-1.183$ \\
\hline & AA & $28(20.9)$ & $13(19.4)$ & $15(22.4)$ & 0.683 & 0.817 & $0.31-2.152$ \\
\hline
\end{tabular}

CTGF, connective tissue growth factor; CRC, colorectal cancer; OR, odds ratio; CI, confidence interval; N/A, not applicable; SNP, single nucleotide polymorphism.

each sample, an average of 7 (range of 5-10) images were captured. The number of images depended upon the length of the tumor-stromal area. Images were adjusted so that the tumor area appeared black and the background white. These images were used to calculate the number of free tumor cells and tumor cell clusters. The black color was then removed so that only the outline of tumor remained (40). Using the tumor outline image, the fractile dimensions were calculated using various software programs; Adobe Photoshop, version 7.0 (Adobe Systems, Inc., San Jose, CA, USA) with the Fovea Pro (Reindeer Graphics, Inc., Asheville, NC, USA) was used for the black/white and the tumor outline images, and ImageJ software (http://imagej.nih.gov/ij/) was used to calculate the fractal dimension value. The CI (ranges 1-5) was obtained by calculating the mean value of these parameters.

Statistical analysis. SPSS, version 20 (IBM SPSS, Armonk, NY, USA) was used for statistical analysis. Continuous variables were measured as the mean and standard deviations. Univariant binary logistic regression was applied to determine different SNPs as risk factors for CRC. The Pearson's $\chi^{2}$ test was used where required to assess the data trends. The CI association was measured using the Fisher's exact test.
Survival was analyzed using the Kaplan-Meier's test. $\mathrm{P} \leq 0.05$ was considered to indicate a statistically significant difference.

\section{Results}

Genetic analysis. The allele frequencies and genotype distributions in the patient and control samples are summarized in Table II. The association between CTGF polymorphisms and occurrence of CRC was compared with the clinicopathological parameters described below. A significant difference in the number of samples with the rs6918698 GG genotype was established between the CRC and the control group samples $(\mathrm{P}=0.05$; Table II). All three genotypes in colon carcinoma sample (CC, GC and GG) were correlated with respective genotypes in normal samples. GG genotype was significantly different in tumor samples as compared with normal samples $(\mathrm{P}=0.05)$. No significant difference was identified in genotypic frequencies of GC between normal and CRC samples $(\mathrm{P}=0.833)$. $\mathrm{CC}$ being a wild type, was considered as a referent. Fig. 1 indicates the different genotypes in rs6918698.

For the rs1931002, rs9493150, rs12526196, rs12527705, rs9399005 and rs12527379 SNPs, no significant association 
Table III. Association between different single nucleotide polymorphisms in connective tissue growth factor and patient survival.

\begin{tabular}{|c|c|c|c|c|c|}
\hline CTGF SNPs & Genotype & $\begin{array}{c}\text { Survival P-value } \\
\text { Kaplan-Meier's test }\end{array}$ & $\begin{array}{c}\text { P-value } \\
\text { Cox-regression test }\end{array}$ & OR & $95 \% \mathrm{CI}$ \\
\hline \multirow[t]{3}{*}{ rs6918698 } & $\mathrm{CC}$ & 0.668 & & 1.00 & Referent \\
\hline & $\mathrm{GC}$ & & 0.374 & 0.752 & $1.402-1.410$ \\
\hline & GG & & 0.612 & 0.83 & $0.405-1.702$ \\
\hline \multirow[t]{3}{*}{ rs1931002 } & GG & 0.367 & & 1.00 & Referent \\
\hline & GA & & 0.174 & 0.445 & $0.139-1.428$ \\
\hline & $\mathrm{AA}$ & & 0.911 & 1.119 & $0.155-8.104$ \\
\hline \multirow[t]{3}{*}{ rs9493150 } & $\mathrm{CC}$ & 0.409 & & 1.00 & Referent \\
\hline & GC & & 0.187 & 1.455 & $0.834-2.538$ \\
\hline & GG & & 0.709 & 1.199 & $0.462-3.115$ \\
\hline \multirow[t]{3}{*}{ rs12526196 } & $\mathrm{TT}$ & 0.868 & & 1.00 & Referent \\
\hline & $\mathrm{TC}$ & & 0.62 & 0.817 & $0.368-1.815$ \\
\hline & $\mathrm{CC}$ & & 0.901 & 1.067 & $0.383-2.971$ \\
\hline \multirow[t]{3}{*}{ rs12527705 } & $\mathrm{TT}$ & 0.489 & & 1.00 & Referent \\
\hline & AT & & 0.876 & 0.938 & $0.421-2.089$ \\
\hline & $\mathrm{AA}$ & & 0.266 & 1.98 & 0.594-6.608 \\
\hline \multirow[t]{3}{*}{ rs9399005 } & GG & 0.123 & & 1.00 & Referent \\
\hline & GA & & 0.48 & 0.772 & $0.377-1.583$ \\
\hline & AA & & 0.132 & 2.182 & $0.791-6.021$ \\
\hline \multirow[t]{3}{*}{ rs12527379 } & GG & 0.599 & & & \\
\hline & GA & & 0.321 & 0.682 & $0.320-1.452$ \\
\hline & AA & & 0.592 & 0.768 & $0.330-1.881$ \\
\hline
\end{tabular}

SNP, single nucleotide polymorphism; CTGF, connective tissue growth factor; OR, odds ratio; CI, confidence interval.

was identified between patients and normal controls (Table II). Clinicopathological parameters, including age, gender, localization and tumor differentiation were analyzed but did not present any significant differences. Tumor penetration (T), lymph node involvement (N) and distance metastasis (M) were also analyzed, but no significant differences were identified $(\mathrm{P}=0.567, \mathrm{P}=0.951$ and $\mathrm{P}=1.00$ respectively).

The 5-year survival data of the patients indicated no significant association between the survival time and the CTGF polymorphisms studied. Statistical results of the survival test were as follows: rs6918698, $\mathrm{P}=0.668$; rs1931002, $\mathrm{P}=0.367$; rs9493150, $\mathrm{P}=0.409$; rs12526196, $\mathrm{P}=0.868$; rs12527705, $\mathrm{P}=0.489$; rs9399005, $\mathrm{P}=0.123$; and $\mathrm{rs} 12527379, \mathrm{P}=0.599$ (Table III, Fig. 2).

Patient clinicopathological data. SNPs in the CTGF gene were determined by pyrosequencing. A total of 224 samples were used in the current study, consisting 112 samples from patients diagnosed with CRC between 2004 and 2009, and 112 samples from healthy blood and plasma donors. Of the patients with CRC, 67 (60\%) were male and 45 (40\%) were female. There were $7(6.2 \%)$ patients $<60$ years of age and $105(93.7 \%)$ that were $>60$. Regarding tumor wall penetration $(\mathrm{T}), 4(3.5 \%)$ were classified as T1; 18 (16\%) T2; $76(68 \%) \mathrm{T} 3$; and 14 (12.5\%) T4. For lymph node metastasis $(\mathrm{N}), 62(55.3 \%)$ patients presented
N0 tumors; 32 (28.5\%), N1; and 17 (15.1\%), N2. With regards to metastasis (M), $8(7.1 \%)$ patients were classified as M1, while the remaining $104(92.8 \%)$ were at the Mx stage. For tumor differentiation, 19 (16.9\%) were low; 71 (63.4\%) were moderate; and 18 (16\%) were at the high differentiation stage.

The tumors were divided into two localizations; right and left colon. There were $73(65.1 \%)$ right-colon, and 39 (34.8\%) left-colon tumors. The survival data demonstrated that $57(50.8 \%)$ patients survived $>5$ years and $55(49.1 \%)$ died within 5 years of CRC diagnosis (Tables III and IV).

SNP and HapMap comparison. When comparing the SNP frequencies to the HapMap data (http://hapmap.ncbi.nlm.nih. gov/cgi-perl/snp_details_phase3?name=rs6918698\&sourc e=hapmap28_B36\&tmpl=snp_details_phase3) for the Central European population, a noticeable difference was observed in genotype frequencies between the tumor, normal and HapMap data in all SNPs (rs6918698, rs1931002, rs9493150, rs12526196, rs12527705, rs9399005 and rs12527379 (Table V).

CI. To assess the CI, images of 64 tumor samples were analyzed (Fig. 3) and the clinicopathological parameters and genetic variation were compared in the seven SNPs, rs6918698, rs1931002, rs9493150, rs12526196, rs9399005, rs12527379 and rs12527705. The CI data was divided into 3 groups: Low 
Table IV. Clinicopathological data of the patients diagnosed with colorectal cancer.

Parameter studied

$\mathrm{N}(\%$ of total $)$

Age

$\leq 60$ years

$>60$ years

$105(93.7)$

Gender

Male

Female

Tumor penetration

$\mathrm{T} 1$

$\mathrm{T} 2$

18 (16)

T3

$76(68)$

T4

$14(12.5)$

Lymph node metastasis

N0

N1

$\mathrm{N} 2$

$17(15.1)$

Metastasis

M1

$\mathrm{Mx}$

Differentiation

Low

Medium

High

Localization

Right colon

Left colon

39 (34.8)

Survival

Survived

Died

$55(49.1)$

CRC, colorectal cancer; $\mathrm{N}$, number of samples.

$(\mathrm{CI}=1)$, medium $(\mathrm{CI}=2,3)$ and high $(\mathrm{CI}=4,5)$. A trend was observed between the genetic variation at SNP rs6918698 and the $\mathrm{CI}$ of the tumor $(\mathrm{P}=0.052)$. No significant association was identified between the other six SNPs CI of tumor (Table VI). Associations of CI with clinicopathological parameters and CTGF SNPs were as follows: Gender, $\mathrm{P}=0.885$; age, $\mathrm{P}=0.321$; $\mathrm{T}$, $\mathrm{P}=0.737 ; \mathrm{N}, \mathrm{P}=0.949 ; \mathrm{M}, \mathrm{P}=0.1$; localization, $\mathrm{P}=0.345$; differentiation, $\mathrm{P}=0.280$; rs6918698, $\mathrm{P}=0.052 ; \mathrm{rs} 1931002, \mathrm{P}=0.453$; rs9493150, $\mathrm{P}=0.370 ; \mathrm{rs} 12526196, \mathrm{P}=0.285 ; \mathrm{rs} 12527705, \mathrm{P}=889$; rs9399005, $\mathrm{P}=0.959$; and $\mathrm{rs} 12527379, \mathrm{P}=0.506$.

\section{Discussion}

CTGF is a multicellular protein involved in promoting endothelial cell growth, adhesion and angiogenesis. CTGF has been studied for its role in various diseases such as sclerosis, kidney fibrosis, hepatic fibrosis, and numerous

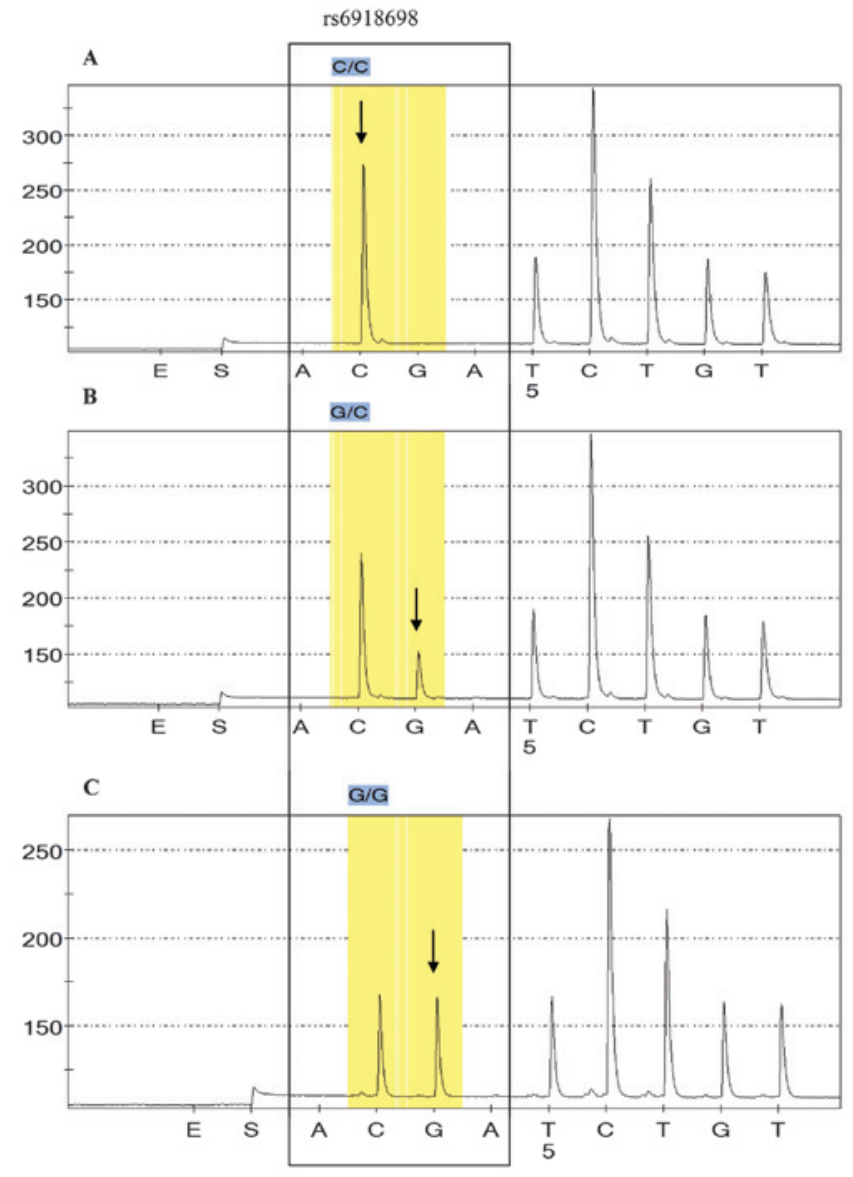

Figure 1. Illustration of rs6918698 single nucleotide polymorphism pyrograms in connective tissue growth factor. (A) Wild type CC genotype. The polymorphism is at the same codon (arrow), in (B) one $\mathrm{C}$ is replaced with $\mathrm{G}$ and in $(\mathrm{C}) \mathrm{CC}$ is replaced by $\mathrm{GG}$.

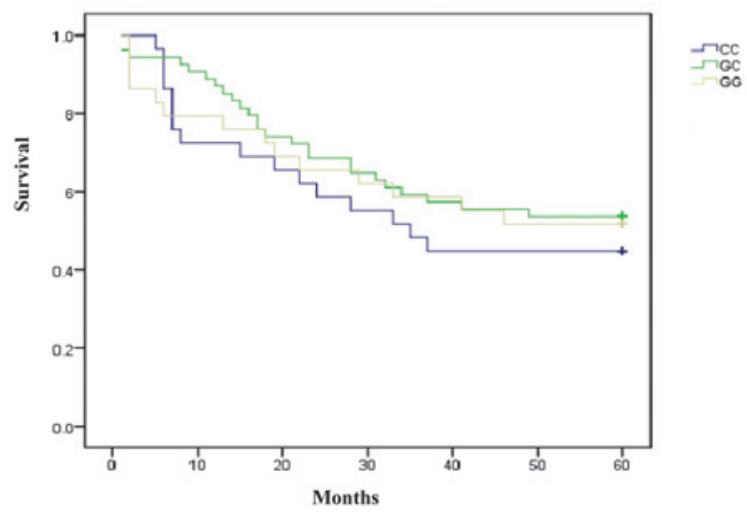

Figure 2. Survival curve presenting the different genotypes associated with rs6918698. There was no significant association between any genotype with survival.

cancers, including CRC $(9,12,17,19,22)$. Previously, only gene expression of CTGF has been analyzed in CRC, thus very little is known about the role of CTGF polymorphisms in this disease (19). In the current study, seven SNPs (rs6918698, rs1931002, rs9493150, rs12526196, rs12527705, rs9399005 and rs12527379) were investigated in the CTGF gene and correlated to the different clinicopathological parameters. Notably, it was demonstrated that the GG genotype of 
Table V. Frequencies of polymorphisms in connective tissue growth factor from the sampled patients compared with HapMap data for the central European population.

\begin{tabular}{|c|c|c|c|c|c|c|}
\hline \multirow[b]{2}{*}{ Genotype } & \multicolumn{2}{|c|}{ Tumor } & \multicolumn{2}{|c|}{ Normal } & \multicolumn{2}{|c|}{ HapMap } \\
\hline & Frequency & Number & Frequency & Number & Frequency & Number \\
\hline \multicolumn{7}{|c|}{ SNP rs6918698 } \\
\hline $\mathrm{CC}$ & 0.26 & 29 & 0.31 & 35 & 0.21 & 13 \\
\hline GC & 0.48 & 54 & 0.54 & 61 & 0.44 & 27 \\
\hline GG & 0.26 & 29 & 0.14 & 16 & 0.35 & 22 \\
\hline \multicolumn{7}{|l|}{ rs1931002 } \\
\hline GG & 0.89 & 100 & 0.87 & 98 & 0.72 & 47 \\
\hline GA & 0.09 & 10 & 0.12 & 13 & 0.23 & 15 \\
\hline AA & 0.018 & 2 & 0.01 & 1 & 0.05 & 3 \\
\hline \multicolumn{7}{|l|}{ rs9493150 } \\
\hline $\mathrm{CC}$ & 0.55 & 62 & 0.6 & 67 & 0.5 & 56 \\
\hline $\mathrm{GC}$ & 0.37 & 41 & 0.36 & 40 & 0.4 & 45 \\
\hline GG & 0.08 & 9 & 0.04 & 5 & 0.1 & 12 \\
\hline \multicolumn{7}{|c|}{ rs12526196 } \\
\hline TT & 0.80 & 89 & 0.84 & 94 & 0.89 & 100 \\
\hline $\mathrm{TC}$ & 0.14 & 16 & 0.16 & 18 & 0.09 & 10 \\
\hline $\mathrm{CC}$ & 0.06 & 7 & 0 & 0 & 0.02 & 2 \\
\hline \multicolumn{7}{|c|}{ rs12527705 } \\
\hline TT & 0.75 & 84 & 0.70 & 78 & N/A & N/A \\
\hline AT & 0.21 & 23 & 0.30 & 34 & N/A & N/A \\
\hline $\mathrm{AA}$ & 0.04 & 5 & 0 & 0 & N/A & N/A \\
\hline \multicolumn{7}{|l|}{ rs9399005 } \\
\hline GG & 0.43 & 29 & 0.51 & 34 & 0.56 & 63 \\
\hline GA & 0.48 & 32 & 0.43 & 29 & 0.34 & 38 \\
\hline $\mathrm{AA}$ & 0.09 & 6 & 0.06 & 4 & 0.106 & 12 \\
\hline \multicolumn{7}{|c|}{ rs12527379 } \\
\hline GG & 0.36 & 24 & 0.25 & 17 & 0.33 & 37 \\
\hline GA & 0.42 & 28 & 0.55 & 37 & 0.56 & 63 \\
\hline AA & 0.22 & 15 & 0.19 & 13 & 0.11 & 13 \\
\hline
\end{tabular}

N/A, not applicable; HapMap, International HapMap Project data.

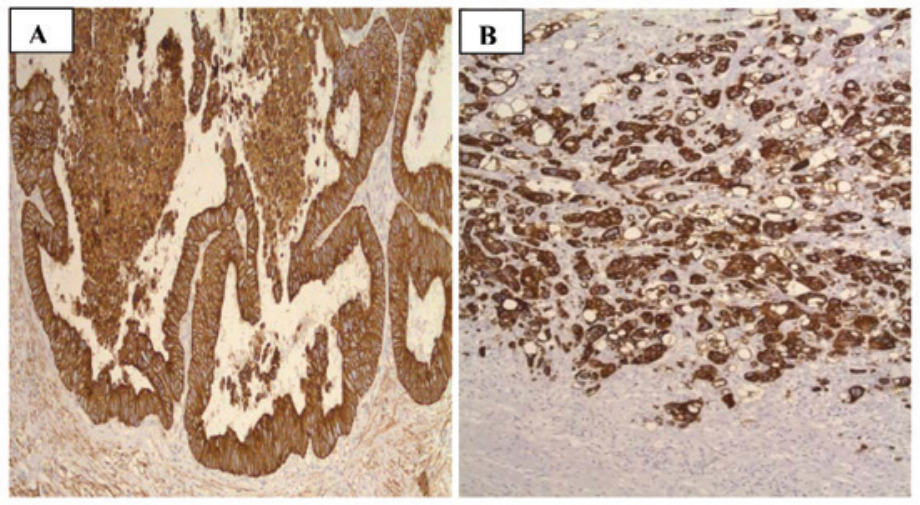

Figure 3. Human colon biopsies exhibiting tumor growth patterns in colon carcinoma. (A) Expansive tumor growth with smooth invasive front (CI=1). (B) The infiltrative growth pattern with highly coarse invasive front and dispersed tumor cells (CI=5). CI, complexity index. 
Table VI. Association of complexity index with clinicopathological parameters of colorectal cancer and single nucleotide polymorphisms in connective tissue growth factor.

\begin{tabular}{|c|c|c|c|c|}
\hline Parameters & Low CI (\% of total) & Medium CI (\% of total) & High CI ( $\%$ of total) & P-value \\
\hline \multicolumn{5}{|l|}{ Gender } \\
\hline Male & $8(12.5)$ & $22(34.49)$ & $10(15.6)$ & \multirow[t]{2}{*}{0.885} \\
\hline Female & $6(9.4)$ & $13(20.3)$ & $5(7.8)$ & \\
\hline \multicolumn{5}{|l|}{ Age } \\
\hline$<60$ years & $0(0)$ & $4(6.2)$ & $0(0)$ & \multirow[t]{2}{*}{0.321} \\
\hline$>60$ years & $14(21.9)$ & $31(84.4)$ & $15(23.4)$ & \\
\hline \multicolumn{5}{|c|}{ Tumor stage $(\mathrm{T})$} \\
\hline $\mathrm{T} 1$ & $1(1.6)$ & $2(3.1)$ & $0(0)$ & \multirow[t]{4}{*}{0.737} \\
\hline $\mathrm{T} 2$ & $4(6.2)$ & $4(6.2)$ & $2(3.1)$ & \\
\hline $\mathrm{T} 3$ & $8(12.5)$ & $25(39.1)$ & $12(18.8)$ & \\
\hline $\mathrm{T} 4$ & $1(1.6)$ & $4(6.2)$ & $1(1.6)$ & \\
\hline \multicolumn{5}{|c|}{ Lymph node metastasis $(\mathrm{N})$} \\
\hline No & $8(12.5)$ & $20(31.7)$ & $8(12.5)$ & \multirow[t]{3}{*}{0.949} \\
\hline N1 & $3(4.8)$ & $9(14.3)$ & $3(4.8)$ & \\
\hline $\mathrm{N} 2$ & $2(3.1)$ & $6(9.5)$ & $4(6.2)$ & \\
\hline \multicolumn{5}{|c|}{ Metastasis (M) } \\
\hline $\mathrm{Mx}$ & $13(20.3)$ & $32(50.0)$ & $14(21.9)$ & \multirow[t]{2}{*}{1} \\
\hline M1 & $1(1.6)$ & $3(4.7)$ & $1(1.6)$ & \\
\hline \multicolumn{5}{|l|}{ Localization } \\
\hline Right colon & $9(14.1)$ & $24(37.5)$ & $13(20.3)$ & \multirow[t]{2}{*}{0.345} \\
\hline Left colon & $5(7.8)$ & $11(17.2)$ & $2(3.1)$ & \\
\hline \multicolumn{5}{|c|}{ Differentiation } \\
\hline Low & $3(4.8)$ & $3(4.8)$ & $4(6.3)$ & \multirow[t]{3}{*}{0.280} \\
\hline Medium & $7(11.1)$ & $26(41.3)$ & $8(12.5)$ & \\
\hline High & $4(6.3)$ & $6(9.5)$ & $2(3.1)$ & \\
\hline \multicolumn{5}{|l|}{ rs6918698 } \\
\hline $\mathrm{CC}$ & $3(4.7)$ & $11(17.2)$ & $3(4.7)$ & \multirow[t]{3}{*}{0.052} \\
\hline $\mathrm{GC}$ & $3(4.7)$ & 17 (26.6) & $10(15.6)$ & \\
\hline GG & $8(12.5)$ & $7(10.9)$ & $2(3.1)$ & \\
\hline \multicolumn{5}{|l|}{ rs1931002 } \\
\hline GG & $14(21.9)$ & $35(54.7)$ & $14(21.9)$ & \multirow[t]{2}{*}{0.453} \\
\hline GA & $0(0)$ & $0(0)$ & 1 (1.6) & \\
\hline \multicolumn{5}{|l|}{ rs9493150 } \\
\hline $\mathrm{CC}$ & $11(17.2)$ & $19(29.7)$ & $9(14.1)$ & \multirow[t]{3}{*}{0.370} \\
\hline $\mathrm{GC}$ & $2(3.1)$ & $13(20.3)$ & $6(9.4)$ & \\
\hline GG & $1(1.6)$ & $3(4.7)$ & $0(0)$ & \\
\hline \multicolumn{5}{|l|}{ rs12526196 } \\
\hline $\mathrm{TT}$ & $13(20.3)$ & $27(42.2)$ & $13(20.3)$ & \multirow[t]{3}{*}{0.285} \\
\hline $\mathrm{TC}$ & $1(1.6)$ & $6(9.4)$ & $0(0)$ & \\
\hline $\mathrm{CC}$ & $0(0)$ & $2(3.1)$ & $2(3.1)$ & \\
\hline \multicolumn{5}{|l|}{ rs12527705 } \\
\hline $\mathrm{TT}$ & $9(14.1)$ & $25(39.1)$ & $11(17.2)$ & 0.889 \\
\hline AT & $4(6.2)$ & $9(14.1)$ & $3(4.7)$ & \\
\hline AA & $1(1.6)$ & $1(1.6)$ & $1(1.6)$ & \\
\hline rs9399005 & & & & \\
\hline GG & $5(7.8)$ & $15(23.4)$ & $6(9.4)$ & 0.959 \\
\hline
\end{tabular}


Table VI. Continued.

\begin{tabular}{lccc}
\hline Parameters & Low CI $(\%$ of total $)$ & Medium CI $(\%$ of total $)$ & High CI $(\%$ of total $)$ \\
\hline GA & $7(10.9)$ & $17(26.6)$ & $8(12.5)$ \\
AA & $2(3.1)$ & $3(4.7)$ & $1(1.6)$ \\
rs12527379 & & & $4(6.2)$ \\
GG & $8(12.5)$ & $11(17.2)$ & $7(10.9)$ \\
GA & $4(6.2)$ & $16(25.0)$ & $4(6.2)$ \\
AA & $2(3.1)$ & $8(12.5)$ & 0.506 \\
\hline
\end{tabular}

CI, complexity index.

rs6918698 was significantly associated with an increased susceptibility to developing CRC $(\mathrm{P}=0.05)$. The other two genotypes, GC and CC in SNP rs6918698, indicated no statistical significance. It may be hypothesized that the $\mathrm{C}$ allele is a protective, and substitution with the $\mathrm{G}$ allele leads to an increased risk for disease development. Similar results were indicated by Fonseca et al (41) who demonstrated that CTGF gene expression is greater when the $C$ is substituted for a $G$ allele in systemic sclerosis (41). This effect may be due to the association between certain genotypes being more frequently involved in transcription and stabilization of mRNA than others in different genes. Previous studies have shown the differential expression of polymorphic variants of the same genes (e.g. myeloperoxidase G463A and TGF $\beta$ C1815T) (42-44). Similar findings were made by Ladwa et al (19) indicating that gene polymorphisms can change their gene expression behavior.

The polymorphisms rs1931002, rs9493150, rs12526196, rs12527705, rs9399005 and rs12527379 were not observed to be correlated with cancer risk, as most of the SNPs produced silent mutations. Polymorphisms in coding regions likley alter the protein function, whereas polymorphisms in the gene regulatory regions may have an effect on gene expression. Pivovarova et al (22) studied SNP rs9493150 in pancreatic fibrosis but did not observe any correlation with disease development. Similar results were obtained in a study by Kovalenko et al (45) on liver fibrosis, in which the rs9493150 and rs9399005 polymorphisms were not associated with the disease. These studies support the current findings indicating that these are silent polymorphisms. In a French population study, SNP rs9399005 was demonstrated to be significantly associated with systemic sclerosis (9). However, in the current study, this SNP was not observed to be significantly associated with the development of CRC, suggesting that this SNP performs a specific role in sclerosis, but not in CRC. The difference in this finding may be due to the different sample populations and methods used for analysis. Similar results were produced in a study by Dessein et al (12), in which CTGF SNPs (rs12526196 and rs1931002) were indicated to serve a significant function in hepatic fibrosis. However, SNP rs12527705 did not present any significant association with tumor growth in CRC in the current study. The resulting proteins of these polymorphisms may have a significant function in fibrosis in organs such as the liver, but are not associated with angiogenesis and tumor growth in CRC.
CTGF has been reported to be involved in binding with TGF $\beta$, thereby enhancing its signalling (45). This demonstrates that polymorphisms are more strongly associated with certain diseases compared with others. In the present study, a high frequency of the rs6918698 GG genotype was identified in patients diagnosed with CRC, but the same SNP studied by Granel et al (9) and Robinson et al (6) was indicated to not be associated with fibrosis, which supports the idea that polymorphisms have different functions in different diseases.

The frequencies of all the SNP genotypes, in the tumor and normal samples, were compared with the HapMap data of the Central European population (CEU) in the current study. All the studied SNPs presented different frequencies to the CEU data, which may be due to the different population samples; the current study used samples from a Swedish population.

As descibed in earlier studies, little is still known about the role of $\mathrm{CCN}$ proteins in cancer, and the results are controversial, thus the role of CTGF in cancer remains undefined. CTGF has an important role in the angiogenesis of breast cancer, and is overexpressed in esophageal adenocarcinoma and CRC $(13,17,19,46)$. Paradoxically, studies by Lin et al (47) and Chang et al (48) indicated that CTGF inhibits metastasis and that overexpression is associated with high survival and good prognosis in lung adenocarcinoma $(47,48)$. In esophageal carcinoma, this overproduction increases the $\beta$-catenin/T-cell factor signalling while opposite results are observed in CRC $(47,49)$. As this divergence is not yet understood, further studies are required.

In the present study, the CI was assessed in 64 tumor samples. The results indicated a trend toward a significant association between CTGF rs6918698 genotype variation and tumor growth pattern $(\mathrm{P}=0.052)$. This demonstrates that genetic variation at rs6918698 has an affect on the phenotype of tumors. Previous studies have indicated that when a tumor metastasizes, its phenotype changes; more aggressive tumors have a more irregular invasive front with high CI $(33,34)$; however, conflicting outcomes have been observed by other researchers $(40,50)$. In the present study, polymorphism rs6918698 was associated with a high risk of developing CRC, which indicates its importance in this disease. To confirm any association between rs6918698 genotypes and the growth patterns of tumors, further studies are required in which a larger number of samples must be examined. In the current study, there was no significant association or trend between 
$\mathrm{CI}$ and the remaining six CTGF polymorphisms. All the SNPs were evaluated for any possible association with clinicopathological parameters, including age, gender, tumor wall penetration, lymph node and systemic metastasis, localization and tumor differentiation. No statistically significant correlations were identified with any of these parameters.

Previous studies have demonstrated that integrin-TGF $\beta$ is involved in cancer development and fibrosis, and that CTGF is a downstream effector of TGF $\beta(13,51)$. It has been indicated that fibrosis can lead to cancer development in various tissues (52), and so polymorphisms in these genes that have an important role in fibrosis should be studied further to clarify their role in cancer development.

In conclusion, the present study was, to the best of our knowledge, the first study conducted in which the association between CTGF polymorphisms, CI and CRC was analyzed. The results, however, did not indicate any significant association between CI, CTGF polymorphism and tumor progression, but a trend was detected between genetic variation at rs6918698 and tumor growth pattern. Another notable finding was that the occurrence of the SNP rs6918698 GG genotype indicated a higher risk of developing CRC. This polymorphism and its association with growth pattern should be investigated in future experiments, using different populations, a larger sample size and different types of tumor, for further understanding of the importance of CTGF SNPs in cancer. This SNP may be a valuable marker in determining risk and progression of different malignant diseases, and a critical step in the future treatment of CRC that could be targeted for chemotherapy.

\section{Acknowledgements}

The current study was funded by the Lions Cancer Research Foundation (Uppsala, Sweden), Örebro University Hospital Research Council and Nyckelfonden, Örebro University Hospital (Örebro, Sweden).

\section{References}

1. Brigstock DR: The connective tissue growth factor/cysteine-rich 61/nephroblastoma overexpressed. Endocr Rev 20: 189-206, 1999.

2. Dhar A and Ray A: The $\mathrm{CCN}$ family proteins in carcinogenesis. Exp Oncol 32: 2-9, 2010.

3. Shimo T, Nakanishi T, Nishida T, et al: Connective tissue growth factor induces the proliferation, migration, and tube formation of vascular endothelial cells in vitro, and angiogenesis in vivo. J Biochem 126: 137-145, 1999.

4. Jacobson A and Cunningham JL: Connective tissue growth factor in tumor pathogenesis. Fibrogenesis Tissue Repair 5 (Suppl 1): S8, 2012.

5. Chen YQ, Sloan-Lancaster J, Berg DT, et al: Differential mechanisms of plasminogen activator inhibitor-1 gene activation by transforming growth factor-beta and tumor necrosis factor-alpha in endothelial cells. Thromb Haemost 86: 1563-1572, 2001.

6. Robinson PM, Smith TS, Patel D, et al: Proteolytic processing of connective tissue growth factor in normal ocular tissues and during corneal wound healing. Invest Ophthalmol Vis Sci 53: 8093-8103, 2012.

7. Brigstock DR: Regulation of angiogenesis and endothelial cell function by connective tissue growth factor (CTGF) and cysteine-rich 61 (CYR61). Angiogenesis 5: 153-165, 2002.

8. Moussad EE and Brigstock DR: Connective tissue growth factor: what's in a name? Mol Genet Metab 71: 276-292, 2000.

9. Granel B, Argiro L, Hachulla E, et al: Association between a CTGF gene polymorphism and systemic sclerosis in a French population. J Rheumatol 37: 351-358, 2010.
10. Wang X, Wan F, Pan J, et al: Tumor size: a non-neglectable independent prognostic factor for gastric cancer. J Surg Oncol 97: 236-240, 2008.

11. Wang B, Carter RE, Jaffa MA, et al; DCCT/EDIC Study Group: Genetic variant in the promoter of connective tissue growth factor gene confers susceptibility to nephropathy in type 1 diabetes. J Med Genet 47: 391-397, 2010.

12. Dessein A, Chevillard C, Arnaud V, et al: Variants of CTGF are associated with hepatic fibrosis in Chinese, Sudanese, and Brazilians infected with schistosomes. J Exp Med 206: 2321-2328, 2009

13. Koliopanos A, Friess H, di Mola FF, et al: Connective tissue growth factor gene expression alters tumor progression in esophageal cancer. World J Surg 26: 420-427, 2002.

14. Zhou ZQ, Cao WH, Xie JJ, et al: Expression and prognostic significance of THBS1, Cyr61 and CTGF in esophageal squamous cell carcinoma. BMC Cancer 9: 291, 2009.

15. Liu L, Li Z, Feng G, You W and Li J: Expression of connective tissue growth factor is in agreement with the expression of VEGF, VEGF-C, -D and associated with shorter survival in gastric cancer. Pathol Int 57: 712-718, 2007.

16. Chen PP, Li WJ, Wang Y, et al: Expression of Cyr61, CTGF, and WISP-1 correlates with clinical features of lung cancer. PLoS One 2: e534, 2007.

17. Chien W, O'Kelly J, Lu D, et al: Expression of connective tissue growth factor $(\mathrm{CTGF} / \mathrm{CCN} 2)$ in breast cancer cells is associated with increased migration and angiogenesis. Int J Oncol 38: 1741-1747, 2011.

18. Zhen Y, Ye Y, Yu X, et al: Reduced CTGF expression promotes cell growth, migration, and invasion in nasopharyngeal carcinoma. PLoS One 8: e64976, 2013.

19. Ladwa R, Pringle H, Kumar R and West K: Expression of CTGF and Cyr61 in colorectal cancer. J Clin Pathol 64: 58-64, 2011.

20. Lin BR, Chang CC, Chen RJ, et al: Connective tissue growth factor acts as a therapeutic agent and predictor for peritoneal carcinomatosis of colorectal cancer. Clin Cancer Res 17: 3077-3088, 2011.

21. Bidwell J, Keen L, Gallagher G, et al: Cytokine gene polymorphism in human disease: on-line databases. Genes Immun 1: 3-19, 1999.

22. Pivovarova O, Fisher E, Dudziak K, et al: A polymorphism within the connective tissue growth factor (CTGF) gene has no effect on non-invasive markers of beta-cell area and risk of type 2 diabetes. Dis Markers 31: 241-246, 2011.

23. Poli F, Boschiero L, Giannoni F, et al: Tumour necrosis factor-alpha gene polymorphism: implications in kidney transplantation. Cytokine 12: 1778-1783, 2000.

24. Awad MR, El-Gamel A, Hasleton P, et al: Genotypic variation in the transforming growth factor-betal gene: association with transforming growth factor-betal production, fibrotic lung disease, and graft fibrosis after lung transplantation. Transplantation 66: 1014-1020, 1998.

25. Bylund JR, Gayheart D, Fleming T, et al: Association of tumor size, location, R.E.N.A.L., PADUA and centrality index score with perioperative outcomes and postoperative renal function. J Urol 188: 1684-1689, 2012.

26. Compton CC: Colorectal carcinoma: diagnostic, prognostic, and molecular features. Mod Pathol 16: 376-388, 2003.

27. Jung CK, Kang YG, Bae JS, et al: Unique patterns of tumor growth related with the risk of lymph node metastasis in papillary thyroid carcinoma. Mod Pathol 23: 1201-1208, 2010.

28. Jass JR: The pathological classification of colorectal cancer. Ann Acad Med Singapore 16: 469-473, 1987.

29. Jass JR, Atkin WS, Cuzick J, et al: The grading of rectal cancer: historical perspectives and a multivariate analysis of 447 cases. Histopathology 41: 59-81, 2002.

30. Franzén LE, Hahn-Strömberg V, Edvardsson H and Bodin L: Characterization of colon carcinoma growth pattern by computerized morphometry: definition of a complexity index. Int J Mol Med 22: 465-472, 2008

31. Ohene-Abuakwa Y and Pignatelli M: Adhesion molecules as diagnostic tools in tumor pathology. Int J Surg Pathol 8: 191-200, 2000.

32. Lee HK, Bier A, Cazacu S, et al: MicroRNA-145 is downregulated in glial tumors and regulates glioma cell migration by targeting connective tissue growth factor. PLoS One 8: e54652, 2013.

33. Mannan A and Hahn-Strömberg V: K-ras mutations are correlated to lymph node metastasis and tumor stage, but not to the growth pattern of colon carcinoma. APMIS 120: 459-468, 2012. 
34. Hahn-Strömberg V, Edvardsson H, Bodin L and Franzén L Tumor volume of colon carcinoma is related to the invasive pattern but not to the expression of cell adhesion proteins. APMIS 117: 205-211, 2009.

35. Gao YB, Xiang ZL, Zhou LY, et al: Enhanced production of CTGF and IL-11 from highly metastatic hepatoma cells under hypoxic conditions: an implication of hepatocellular carcinoma metastasis to bone. J Cancer Res Clin Oncol 139: 669-679, 2013

36. Xie H, Zhao Y, Caramuta S, Larsson C and Lui WO: miR-205 expression promotes cell proliferation and migration of human cervical cancer cells. PLoS One 7: e46990, 2012.

37. Heinzle C, Gsur A, Hunjadi M, et al: Differential effects of polymorphic alleles of FGF receptor 4 on colon cancer growth and metastasis. Cancer Res 72: 5767-5777, 2012.

38. Zhong R, Liu L, Zou L, et al: Genetic variations in the TGF $\beta$ signaling pathway, smoking and risk of colorectal cancer in a Chinese population. Carcinogenesis 34: 936-942, 2013.

39. Jang MJ, Jeon YJ, Kim JW, et al: Association of VEGF and KDR single nucleotide polymorphisms with colorectal cancer susceptibility in Koreans. Mol Carcinog 52 (Suppl 1): E60-69, 2013

40. Hahn-Strömberg V, Edvardsson H, Bodin L and Franzén L: Disturbed expression of E-cadherin, beta-catenin and tight junction proteins in colon carcinoma is unrelated to growth pattern and genetic polymorphisms. APMIS 116: 253-262, 2008

41. Fonseca C, Lindahl GE, Ponticos M, et al: A polymorphism in the CTGF promoter region associated with systemic sclerosis. N Engl J Med 357: 1210-1220, 2007.

42. Greenawalt DM, Sieberts SK, Cornelis MC, et al: Integrating genetic association, genetics of gene expression, and single nucleotide polymorphism set analysis to identify susceptibility Loci for type 2 diabetes mellitus. Am J Epidemiol 176: 423-430, 2012.

43. Katakami N, Kume S, Kaneto H, et al: Association of myeloperoxidase G-463A gene polymorphism with diabetic nephropathy. Endocr J 60: 457-471, 2012.
44. Guo H, Bao Z, Li J, et al: Molecular characterization of TGF- $\beta$ type I receptor gene (Tgfbrl) in Chlamys farreri, and the association of allelic variants with growth traits. PLoS One 7: e51005, 2012.

45. Kovalenko E, Tacke F, Gressner OA, et al: Validation of connective tissue growth factor (CTGF/CCN2) and its gene polymorphisms as noninvasive biomarkers for the assessment of liver fibrosis. J Viral Hepat 16: 612-620, 2009.

46. Davies SR, Davies ML, Sanders A, et al: Differential expression of the CCN family member WISP-1, WISP-2 and WISP-3 in human colorectal cancer and the prognostic implications. Int J Oncol 36: 1129-1136, 2010.

47. Lin BR, Chang CC, Che TF, et al: Connective tissue growth factor inhibits metastasis and acts as an independent prognostic marker in colorectal cancer. Gastroenterology 128: 9-23, 2005.

48. Chang CC, Lin MT, Lin BR, et al: Effect of connective tissue growth factor on hypoxia-inducible factor 1alpha degradation and tumor angiogenesis. J Natl Cancer Inst 98: 984-995, 2006.

49. Deng YZ, Chen PP, Wang Y, et al: Connective tissue growth factor is overexpressed in esophageal squamous cell carcinoma and promotes tumorigenicity through beta-catenin-T-cell factor/Lef signaling. J Biol Chem 282: 36571-36581, 2007.

50. Victoria HS, Henrik E, Lennart B and Lennart F: Claudin 1 and claudin 7 gene polymorphisms and protein derangement are unrelated to the growth pattern and tumor volume of colon carcinoma. Int J Biomed Sci 6: 96-102, 2010.

51. Margadant $\mathrm{C}$ and Sonnenberg A: Integrin-TGF-beta crosstalk in fibrosis, cancer and wound healing. EMBO Rep 11: 97-105, 2010.

52. Radisky DC, Kenny PA and Bissell MJ: Fibrosis and cancer: do myofibroblasts come also from epithelial cells via EMT? J Cell Biochem 101: 830-839, 2007. 